\title{
EFFECT OF COCONUT WATER IN TRIS EGG YOLK CITRATE EXTENDER ON CAUDA EPIDIDYMAL BUCK SPERMATOZOA MOTILITY PRESERVED AT REFRIGERATION TEMPERATURE
}

\author{
R. V. BALDANiYA ${ }^{1}$, N. F. ChaUdhari², L. C. MOdi², C. M. PATEL ${ }^{3}$, \\ G. PURI ${ }^{4}$ AND J. M. PATEL ${ }^{4}$
}

\begin{abstract}
${ }^{1}$ Mobile Veterinary Dispensary, Department of Animal Husbandry, Gujarat
${ }^{2}$ Department of Veterinary Gynaecology and Obstetrics, College of Veterinary Science and Animal Husbandry, Navsari Agricultural University, Navsari- 396 450, Gujarat

${ }^{3}$ Veterinary Officer, Sumul Dairy, Surat, Gujarat

${ }^{4}$ College of Veterinary Science and Animal Husbandry, Navsari Agricultural University, Navsari, Gujarat
\end{abstract}

\begin{abstract}
The present research work was carried out on total ten (10) pairs of testis from ten (10) matured non-descript buck irrespective of breed presented for slaughter at government approved slaughter house, over a period of four months from August to November, 2018. The objective of present study was to evaluate the effect of coconut water supplementation in tris egg yolk citrate extender on cauda epididymal buck spermatozoa motility preserved at refrigeration temperature. The paired cauda epididymal spermatozoa were diluted with tris egg yolk citrate extender and made a five equal aliquots i.e. T1 to $\mathrm{T} 5$. $\mathrm{T} 1$ is kept as a control while $\mathrm{T} 2, \mathrm{T3}, \mathrm{T} 4$ and $\mathrm{T} 5$ were supplemented with $5,10,15$ and $20 \%$ coconut water and preserved at refrigeration temperature $\left(4-5^{\circ} \mathrm{C}\right)$. The sperm motility and motility degeneration rate (MDR) were measured at different time intervals up to $48 \mathrm{hrs}$. The highest percentage of sperm motility, irrespective of preservation time, was found in T2 $(59.80 \pm 3.49 \%)$ followed byT3 $(53.40 \pm 3.83 \%)$, T4 $(46.35 \pm 4.19 \%)$, T1 $(43.05 \pm 4.53 \%)$ and T5 $(42.30 \pm 4.35 \%)$ groups in paired cauda epididymis buck spermatozoa at refrigeration temperature. Further, the percentage of sperm motility was decreased with increased preservation time. The least percentage of motility degeneration rate, irrespective of preservation time, was found in T2 $(24.03 \pm 3.74 \%)$ followed by T3 $(34.92 \pm 3.79 \%)$, T4 (47.03 $\pm 3.93 \%)$, T1 (51.59 $\pm 4.41 \%)$ and T5 $(53.16 \pm 3.86 \%)$ groups in paired cauda epididymal buck spermatozoa at refrigerated temperature, respectively.
\end{abstract}

Key words: Buck, Cauda epididymal, Coconut water, Motility, Spermatozoa

Goat semen preservation with suitable extenders for extended period of time is most essential for the success of AI. Goat semen can be preserved either at room temperature temporarily, at refrigerated temperature for 24-48 hours (Ferdinand et al., 2012) or cryopreserved (Beltran et al., 2013) for long term storage. However, only limited period of storage at ambient temperature (Ferdinand et al., 2012) as well as poor quality on post-cryopreservation (Yimer et al., 2014) encourage the workers to preserve the semen at refrigerated temperature which is cheaper and more feasible than cryopreservation of semen which is not possible everywhere due to lack of cryopreservation facilities.

The presence of sugars, amino acids, minerals and vitamins found in coconut water, are not only nutrients but also cryoprotectants in addition to presence of antioxidants (Yong et al., 2009). 
Coconut water is poor in phospholipids and rich in complex organic molecules, such as proline, glycine, glutamic acid and indole-acetic acid (IAA) which protects and extends the life span of spermatozoa, based on cell membrane protection that reinforces its molecular structure (Nunes and Combarnous, 1995). Barros and Toniolli (2011) reviewed the potential effects of coconut water on semen technology and reported that its utilization as an extender is important because it is an easily prepared, cheap alternative for semen transport over small distances and for use in artificial insemination programs in several species.

Sperm motility is most important criteria for any semen sample for further processing and storage for future use in AI programme. There is a little information regarding epididymal sperm retrieval and preservation at refrigerated temperature. Similarly, except few reports on addition of certain fruit filtrate as non-enzymatic antioxidant in buck epididymal semen preservation, no literature was found on use of coconut water as buck epididymal spermatozoa preservative, particularly in India. Therefore, the present study was undertaken to evaluate the effect of coconut water in tris egg yolk citrate extender on cauda epididymal buck spermatozoa motility preserved at refrigeration temperature.

\section{MATERIALS AND METHODS}

Sample collection and processing: Ten pairs of testicles were collected immediately after slaughter under strict hygienic conditions from apparently healthy matured non-descript buck irrespective of breed at government approved slaughter house and transferred to the laboratory in ice packs as early as possible. The laboratory processing of testes was carried out within 30 minutes of reaching the laboratory. Testes were washed and cleaned with RO water. Fascia, blood vessels and sheath of testes were removed with the help of BP blade and thumb forceps. Care was taken to prevent the damage to the epididymis. Spermatozoa were retrieved separately from the right and left cauda epididymis at room temperature by the incision method. Several small incisions were made on the cauda of epididymides with a BP blade to enable spermatozoa swim out in to $5 \mathrm{~mL}$ pre warmed $\left(37^{\circ} \mathrm{C}\right)$ tris egg yolk citrate (TEYC) diluter in a petri dish. Cauda epididymal sperm samples having $\geq 70 \%$ individual motility were selected for further analysis and extended with TEYC diluter to make a final volume of 20 $\mathrm{mL}$. Retrieved spermatozoa of right and left cauda epididymis were extended with diluter separately.

Preparation of coconut water: Coconut water (CW) was collected on the day of experiment from a tender, green, healthy and undamaged coconut fruits. The coconut water collected from coconut fruits was first filtered through Whatman filter paper no. 4 followed by syringe filter $(0.2 \mu)$. Finally, it was centrifuged at least for 5 minutes at $3000 \mathrm{rpm}$ in centrifuge machine and the supernatant from each tube was obtained carefully in a sterile glass bottle.

Experimental groups: To study the effect of coconut water as an additive on refrigerated cauda epididymal spermatozoa motility, $20 \mathrm{~mL}$ of diluted samples from individual epididymides were divided into five aliquots (T1 to T5) and supplemented with different concentrations of coconut water. T1 is kept as a control while $\mathrm{T} 2, \mathrm{~T} 3, \mathrm{~T} 4$ and $\mathrm{T} 5$ were supplemented with 5, 10, 15 and $20 \%$ coconut water, respectively and preserved at refrigeration temperature $\left(4-8^{\circ} \mathrm{C}\right)$ up to $48 \mathrm{hrs}$ and evaluated at every $12 \mathrm{hrs}$ interval at $37^{\circ} \mathrm{C}$ temperature in water bath.

Evaluation of sperm motility (\%): Individual sperm motility from the extended samples was determined by placing a small drop of the diluted sample on a warmed glass slide covered with cover slip using phase contrast microscope with warm stage $\left(37^{\circ} \mathrm{C}\right)$. The proportion of progressively motile spermatozoa was expressed in percentage from 0 to 100 with intervals of $5 \%$. To decide motility more accurately, minimum four to five different microscopic fields were assessed. 
Evaluation of motility degeneration rate (MDR) (\%): To determine the motility degeneration rate (MDR), the motility was examined at $0,12,24,36$ and 48 hours. At the end of each time the motility degeneration rates were calculated by using the following formula.

$\begin{aligned} & \text { MDR at } \\ & \text { various } \\ & \text { hrs }(\%)\end{aligned}=\frac{\text { Motility }(0 \mathrm{hrs})-\text { Motility at various hrs }}{\text { Motility }(0 \mathrm{hrs})} \times 100$

(Campos et al., 2004)

Corresponding values of motility at $12,24,36$ and $48 \mathrm{hrs}$ were processed with the above formula to calculate MDR at various hrs.

Statistical Analysis: The data pertaining to various aspects were suitably tabulated and analysed using R-3.3.2 software. The differences among the parameter means were carried out using appropriate statistical methods, viz. ANOVA, DNMRT (Duncan's New Multiple Range Test). The mean differences were considered significant at $\mathrm{p}<0.05, \mathrm{p}<0.01$ and $\mathrm{p}<0.001$.

\section{RESULTS}

Sperm Motility (\%): The initial and post-chilling motility of paired (right and left) cauda epididymal spermatozoa supplemented with different concentrations of coconut water in tris egg yolk citrate extender was monitored in all the groups at different time intervals and presented in Table 1.

The initial sperm motility differed nonsignificantly at 0 hour between $\mathrm{T} 1(74.00 \pm 1.96)$,

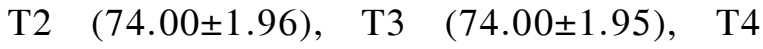
$(74.00 \pm 1.95)$ and T5 $(74.00 \pm 1.95)$ groups. Further, at 12 hours post-chilling it was observed significantly $(\mathrm{p}<0.001)$ lower in $\mathrm{T} 1$ group $(50.25 \pm 3.19)$ as compared to $\mathrm{T} 2(67.50 \pm 2.23)$ and T3 (59.50 \pm 2.72$)$ groups while, non-significantly lower as compared to T4 $(51.50 \pm 2.93)$ and higher as compared to T5 $(46.00 \pm 2.60)$ groups. Similarly, at 24 hours post-chilling it was found significantly $(\mathrm{p}<0.001)$ lower in $\mathrm{T} 1(37.75 \pm 3.21)$ as compared to $\mathrm{T} 2(60.00 \pm 2.50)$ and $\mathrm{T} 3$
$(49.75 \pm 3.25)$ groups but non-significantly lower as compared to T4 $(39.25 \pm 3.16)$ and higher as compared to T5 $(34.50 \pm 2.87)$ groups. However, after 36 hours post-chilling the sperm motility was significantly $(\mathrm{p}<0.001)$ lower in $\mathrm{T} 1(30.00 \pm 3.67)$ as compared to T2 (53.25 \pm 2.73$)$, T3 (46.50 2.62$)$ and T4 (38.50 \pm 2.79$)$ groups, while nonsignificantly differed with T5 $(32.25 \pm 3.06)$ group. Lastly, at 48 hours post-chilling it was found nonsignificantly lower in $\mathrm{T} 1(23.25 \pm 3.27)$ as compared to T4 $(28.50 \pm 2.95)$ and $\mathrm{T} 5$ $(24.75 \pm 3.11)$ groups and significantly $(\mathrm{p}<0.001)$ lower as compared to T2 $(44.25 \pm 2.82)$ and T3 $(37.25 \pm 2.94)$ groups. The overall mean percentage of sperm motility irrespective of various treatment groups reduced with increasing preservation time as $74.00 \pm 1.94,54.95 \pm 3.29$, $44.25 \pm 3.61,40.10 \pm 3.55$ and $31.60 \pm 3.47 \%$ at 0 , $12,24,36$ and 48 hours, respectively.

Moreover, the sperm motility was found significantly $(\mathrm{p}<0.001)$ higher in $\mathrm{T} 1, \mathrm{~T} 2, \mathrm{~T} 3, \mathrm{~T} 4$, and T5 groups at $0 \mathrm{hr}(74.00 \pm 1.96,74.00 \pm 1.96$, $74.00 \pm 1.95,74.00 \pm 1.95$ and $74.00 \pm 1.95)$ as compared to $12 \mathrm{hrs}(50.25 \pm 3.19,67.50 \pm 2.23$, $59.50 \pm 2.72,51.50 \pm 2.93$ and $46.00 \pm 2.60), 24 \mathrm{hrs}$ $(37.75 \pm 3.21,60.00 \pm 2.50,49.75 \pm 3.25,39.25 \pm 3.16$ and $34.50 \pm 2.87), 36 \mathrm{hrs}(30.00 \pm 3.67,53.25 \pm 2.73$, $46.50 \pm 2.62,38.50 \pm 2.79$ and $32.25 \pm 3.06)$ and 48 hrs $(23.25 \pm 3.27,44.25 \pm 2.82,37.25 \pm 2.94$, $28.50 \pm 2.95$ and $24.75 \pm 3.11)$ post-chilling. The overall mean values of sperm motility irrespective of preservation time was found highest in T2 (59.80 \pm 3.49$)$ followed by T3 $(53.40 \pm 3.83)$, T4 $(46.35 \pm 4.19), \quad \mathrm{T} 1 \quad(43.05 \pm 4.53)$ and $\mathrm{T} 5$ $(42.30 \pm 4.35)$ groups which propose the beneficial effect of coconut water at $5 \%$ however, deleterious effect at higher concentration (20\%) as an additive when supplemented in tris egg yolk citrate extender for preservation of buck semen at refrigerated temperature, particularly for sperm motility.

Motility degeneration rate (MDR) (\%): The percentage of motility degeneration rate for paired (right and left) cauda epididymal spermatozoa supplemented with different concentrations of coconut water in tris egg yolk citrate extender was 
TABLE 1. Effect of different concentrations of tris coconut water extender and storage duration on motility (\%) of paired cauda epididymal buck spermatozoa preserved at refrigeration temperature (Mean \pm SE)

\begin{tabular}{|c|c|c|c|c|c|c|c|c|}
\hline \multirow{2}{*}{ Groups } & \multicolumn{5}{|c|}{$\begin{array}{c}\text { Sperm motility }(\%) \\
(n=20 \text { testicle })\end{array}$} & \multirow{2}{*}{$\begin{array}{c}\text { Overall } \\
(n=50)\end{array}$} & \multirow{2}{*}{$\begin{array}{c}\mathbf{F} \\
\text { value }\end{array}$} & \multirow{2}{*}{$\begin{array}{c}\mathbf{P} \\
\text { value }\end{array}$} \\
\hline & O hr & $12 \mathrm{hr}$ & $24 \mathrm{hr}$ & $36 \mathrm{hr}$ & $48 \mathrm{hr}$ & & & \\
\hline $\mathrm{T} 1$ & $74.00 \pm 1.96_{\mathrm{v}}$ & $50.25 \pm 3.19^{\mathrm{cd}}$ & $37.75 \pm 3.21^{\mathrm{c}}$ & $30.00 \pm 3.67_{y}^{d}$ & $23.25 \pm 3.27^{\mathrm{c}}$ & $43.05 \pm 4.53$ & $75.84^{* * *}$ & 0.000 \\
\hline $\mathrm{T} 2$ & $74.00 \pm 1.96_{v}$ & $67.50 \pm 2.23^{\mathrm{a}}$ & $60.00 \pm 2.50^{\mathrm{a}}$ & $53.25 \pm 2.73^{\mathrm{a}}$ & $44.25 \pm 2.82^{\mathrm{a}}{ }_{\mathrm{z}}$ & $59.80 \pm 3.49$ & $68.52 * * *$ & 0.000 \\
\hline $\mathrm{T} 3$ & $74.00 \pm 1.95_{w}$ & $59.50 \pm 2.72^{b}$ & $49.75 \pm 3.25_{y}^{b}$ & $46.50 \pm 2.62^{\mathrm{b}}$ & $37.25 \pm 2.94_{\mathrm{z}}^{\mathrm{b}}$ & $53.40 \pm 3.83$ & $64.40 * * *$ & 0.000 \\
\hline $\mathrm{T} 4$ & $74.00 \pm 1.95_{w}$ & $51.50 \pm 2.93^{\mathrm{c}}$ & $39.25 \pm 3.16_{y}^{c}$ & $38.50 \pm 2.79_{\mathrm{y}}^{\mathrm{c}}$ & $28.50 \pm 2.95^{\mathrm{c}}{ }_{\mathrm{z}}$ & $46.35 \pm 4.19$ & $93.46^{* * *}$ & 0.000 \\
\hline $\mathrm{T} 5$ & $74.00 \pm 1.95_{w}$ & $46.00 \pm 2.60^{\mathrm{d}}$ & $34.50 \pm 2.87_{y}^{\mathrm{c}}$ & $32.25 \pm 3.06_{\mathrm{y}}^{\mathrm{d}}$ & $24.75 \pm 3.11^{\mathrm{c}}{ }_{\mathrm{z}}$ & $42.30 \pm 4.35$ & $119.78^{* * *}$ & 0.000 \\
\hline Overall & $74.00 \pm 1.94$ & $54.95 \pm 3.29$ & $44.25 \pm 3.61$ & $40.10 \pm 3.55$ & $31.60 \pm 3.47$ & - & - & - \\
\hline F value & 0.0 & $24.02 * * *$ & $25.81 * * *$ & $21.89 * * *$ & $18.82 * * *$ & - & - & - \\
\hline P value & 1.0 & 0.000 & 0.000 & 0.000 & 0.000 & - & - & - \\
\hline
\end{tabular}

${ }^{a-d}$ Means with different superscript within a column (between the groups) differs significantly at $\mathrm{p}<0.001$

${ }^{\mathrm{v}-\mathrm{z}}$ Means with different subscript between a column (between time intervals) differs significantly at $\mathrm{p}<0.001$

**** Significant at $\mathrm{p}<0.001$

T1-Control; T2- Tris CW 5\%; T3-Tris CW 10\%; T4-Tris CW 15\%; T5-Tris CW 20\%

TABLE 2. Effect of different concentrations of tris coconut water extender and storage duration on motility degeneration rate (MDR, \%) of paired cauda epididymal buck spermatozoa preserved at refrigeration temperature (Mean $\pm \mathrm{SE})$

\begin{tabular}{|c|c|c|c|c|c|c|c|}
\hline \multirow{2}{*}{ Groups } & \multicolumn{4}{|c|}{$\begin{array}{c}\operatorname{MDR}(\%) \\
(n=10)\end{array}$} & \multirow[t]{2}{*}{$\begin{array}{c}\text { Overall } \\
(n=50)\end{array}$} & \multirow[t]{2}{*}{$\begin{array}{c}\mathbf{F} \\
\text { value }\end{array}$} & \multirow[t]{2}{*}{$\begin{array}{c}\mathbf{P} \\
\text { value }\end{array}$} \\
\hline & $12 \mathrm{hr}$ & $24 \mathrm{hr}$ & $36 \mathrm{hr}$ & $48 \mathrm{hr}$ & & & \\
\hline $\mathrm{T} 1$ & $32.19 \pm 3.55_{z}^{b}$ & $49.15 \pm 3.55^{\mathrm{ab}}$ & $59.78 \pm 4.11^{\mathrm{a}}{ }_{\mathrm{x}}$ & $65.23 \pm 4.20^{\mathrm{a}}$ & $51.59 \pm 4.41$ & $18.59 * * *$ & 0.000 \\
\hline $\mathrm{T} 2$ & $8.82 \pm 1.98_{z}^{d}$ & $18.94 \pm 2.77_{y}^{\mathrm{d}}$ & $28.07 \pm 3.01_{x}^{\mathrm{d}}$ & $40.30 \pm 3.09^{c}{ }_{w}$ & $24.03 \pm 3.74$ & $58.01 * * *$ & 0.000 \\
\hline $\mathrm{T} 3$ & $20.43 \pm 2.91^{\mathrm{c}}$ & $32.87 \pm 3.61_{y}^{c}$ & $37.18 \pm 2.91_{\mathrm{y}}^{\mathrm{c}}$ & $49.17 \pm 3.17^{b}$ & $34.92 \pm 3.79$ & $27.27 * * *$ & 0.000 \\
\hline $\mathrm{T} 4$ & $30.60 \pm 3.12^{b}$ & $43.08 \pm 3.18_{y}^{b}$ & $47.37 \pm 3.35_{\mathrm{x}}^{\mathrm{b}}$ & $61.55 \pm 3.29^{\mathrm{a}}{ }_{\mathrm{w}}$ & $47.03 \pm 3.93$ & $30.72 * * *$ & 0.000 \\
\hline $\mathrm{T} 5$ & $37.90 \pm 2.88_{z}^{a}$ & $50.76 \pm 3.18_{\mathrm{y}}^{\mathrm{a}}$ & $57.97 \pm 3.38^{a}{ }_{x}^{a}$ & $66.03 \pm 3.61^{\mathrm{a}}{ }_{\mathrm{w}}$ & $53.16 \pm 3.86$ & $24.26 * * *$ & 0.000 \\
\hline $\begin{array}{l}\text { Overall } \\
(n=50)\end{array}$ & $25.98 \pm 3.69$ & $38.95 \pm 3.99$ & $46.08 \pm 4.10$ & $56.45 \pm 3.99$ & - & - & - \\
\hline F value & $32.3^{* * *}$ & $29.53 * * *$ & $26.42 * * *$ & $16.17 * * *$ & - & - & - \\
\hline $\mathrm{P}$ value & 0.000 & 0.000 & 0.000 & 0.000 & - & - & - \\
\hline
\end{tabular}

${ }^{\mathrm{a}-\mathrm{d}}$ Means with different superscript within a column (between the groups) differs significantly at $\mathrm{p}<0.001$

${ }^{\mathrm{w}-\mathrm{z}}$ Means with different subscript between a column (between time intervals)differs significantly at $\mathrm{p}<0.001$

**** Significant at $\mathrm{p}<0.001$

T1-Control; T2- Tris CW 5\%; T3-Tris CW 10\%; T4-Tris CW 15\%; T5-Tris CW 20\%

monitored in all the groups at different time intervals and presented in Table 2.

The percentage of MDR observed at 12 hours post- chilling was significantly $(\mathrm{p}<0.001)$ higher in T5 $(37.90 \pm 2.88)$ as compared to $\mathrm{T} 1(32.19 \pm 3.55)$, T2 (8.82 \pm 1.98$), \quad$ T3 $(20.43 \pm 2.91), \quad$ T4 (30.60 \pm 3.12$)$ groups. Further, at 24 and 36 hours 
post-chilling it was found significantly $(\mathrm{p}<0.001)$ higher in T5 $(50.76 \pm 3.18$ and $57.97 \pm 3.38)$ as compared to $\mathrm{T} 2(18.94 \pm 2.77$ and $28.07 \pm 3.01)$, T3 $(32.87 \pm 3.61$ and $37.18 \pm 2.91)$ and $\mathrm{T} 4$ $(43.08 \pm 3.18$ and $47.37 \pm 3.35)$ groups while nonsignificantly higher as compared to $\mathrm{T} 1$ $(49.15 \pm 3.55$ and $59.78 \pm 4.11)$ group, respectively. However at 48 hours post-chilling it was found significantly $(\mathrm{p}<0.001)$ higher in T5 $(66.03 \pm 3.61)$ as compared to $\mathrm{T} 2(40.30 \pm 3.09)$ and $\mathrm{T} 3$ $(49.17 \pm 3.17)$ groups whereas, non-significantly higher as compared to $\mathrm{T} 1(65.23 \pm 4.20)$ and $\mathrm{T} 4$ $(61.55 \pm 3.29)$ groups. The overall mean value of MDR irrespective of various groups inclined with increasing preservation time as $25.98 \pm 3.69$, $38.95 \pm 3.99,46.08 \pm 4.10$ and $56.45 \pm 3.99$ at 12 , 24,36 and 48 hours, respectively.

Moreover, in T1, T2, T3, T4 and T5 groups the MDR was found significantly $(\mathrm{p}<0.001)$ lower at 12 hours $(32.19 \pm 3.55,8.82 \pm 1.98$, $20.43 \pm 2.91,30.60 \pm 3.12$ and $37.90 \pm 2.88)$ as compared at 24 hours $(49.15 \pm 3.55,18.94 \pm 2.77$, $32.87 \pm 3.61,43.08 \pm 3.18$ and $50.76 \pm 3.18), 36$ hours $(59.78 \pm 4.11,28.07 \pm 3.01,37.18 \pm 2.91$, $47.37 \pm 3.35$ and $57.97 \pm 3.38$ ) and 48 hours $(65.23 \pm 4.20, \quad 40.30 \pm 3.09, \quad 49.17 \pm 3.17$, $61.55 \pm 3.29$ and $66.03 \pm 3.61)$ post-chilling. The overall mean value of MDR irrespective of time intervals was found highest in T5 $(53.16 \pm 3.86)$ followed by $\mathrm{T} 1(51.59 \pm 4.41), \mathrm{T} 4(47.03 \pm 3.93)$, $\mathrm{T} 3(34.92 \pm 3.79)$ and $\mathrm{T} 2(24.03 \pm 3.74)$ groups.

Lowest MDR was found in T2 group as compared to all other groups at various time intervals during preservation indicating the beneficial effect of coconut water at lower concentration $(5 \%)$ on sperm motility when added in tris egg yolk citrate extender for preservation of buck semen at refrigerated temperature.

\section{DISCUSSION}

The findings of the present study regarding sperm motility were in close agreement with the findings of Daramola et al. (2016) who found significantly higher $(\mathrm{p}<0.05)$ motility in coconut water extenders at various concentration with highest motility at $10 \%(39.8 \pm 4.16$ Vs $24.5 \pm 5.63 \%)$ as compared to the control for cryopreserved West African Dwarf (WAD) bucks spermatozoa. Similarly, Lima et al. (2013) also reported significantly higher values of motility for crossbred goat cauda epididymal spermatozoa stored at $4^{\circ} \mathrm{C}$ up to 48 hours diluted in coconut water-egg yolk (CW$\mathrm{EY}$ ) extender as compared to physiologic solution with $0.5 \%$ glucose and egg yolk (PSEY), ultra-heat treated long-life extender (UHT) and milk-based extender or ME-EY consisting of long-life ultra-heat-treated milk with $2.5 \%$ egg yolk (v/v).

Further, El-Sheshtawy et al. (2017) also reported the highly significant percentage for motility $(48.78 \pm 1.57)$ in $4 \%$ coconut water based extender as compared to control, $6 \%$ and $8 \%$ coconut water based extender $(40.00 \pm 2.83,29.38 \pm 1.99$ and $30.00 \pm 1.34$, respectively) in freeze-thawed cattle semen which again strongly supports the findings of present study. Similarly, Puja et al. (2018) reported significantly higher progressive motility in pasteurized coconut water (PCW) compared to unpasteurized coconut water $(\mathrm{CW})$ based extender in Kintamani dog semen preserved at $4^{\circ} \mathrm{C}$. Further, they also reported that, PCW based extender preserved the motility of more than $60 \%$ of the spermatozoa up to day 5 post-sampling. Similarly, Cardoso et al. (2005) reported higher sperm motility after freezing/ thawing in natural coconut water $(91.7 \% / 65.8 \%)$ as compared to powdered coconut water $(91.3 \%)$ $55 \%$ ) in canine which also supports the results of present study. Likewise, Luzardo et al. (2010) found a significantly higher values for motility in deionized coconut water based extender (41.9\%) as compare to control (36.9\%) extender in frozen boar semen. In the same way, Almeida and Soares (2002) reported that, coconut water seems to be ideal natural diluents for short period in vitro storage of honey bee semen. Similarly, Silva et al. (2011) reported significantly higher sperm motility after cryopreservation and thawing in powdered coconut water containing extender ACP-109c $(26.5 \pm 2.6 \%)$ as compared to TRIS extender $(9.7 \pm 2.6 \%)$ in agouti. 
However, contrary to the findings of present study Juma (2017) reported no significant difference in sperm motility between coconut water based egg-yolk-containing extender (COC) and Optixcell (OPT) extender processed with and without seminal plasma for preservation of Alpine goat semen at room temperature $\left(21-23^{\circ} \mathrm{C}\right)$ or chilled $\left(1-4^{\circ} \mathrm{C}\right)$ temperature. Similarly, Mayombo (2017) also reported non-significant difference in sperm motility among tris egg yolk extender (TEYE), soybean milk extender (SBME) and coconut water based extenders (COWE) for preservation of Nguni bull at different temperatures i.e. room temperature $\left(\mathrm{RT}, 25^{\circ} \mathrm{C}\right)$, refrigerator temperature $\left(\mathrm{RF}, 4^{\circ} \mathrm{C}\right.$ ) and cryopreserved in LN2 (FR, $196^{\circ} \mathrm{C}$ ) after three days of storage.

The findings of the present study regarding motility degradation rate was in close agreement with the findings of Lima et al. (2013) who reported lower motility degradation rate in coconut water-egg yolk extender (CW-EY) as compared to other extenders used for storage of cauda epididymal spermatozoa from crossbred goat at refrigerated temperature $\left(4^{\circ} \mathrm{C}\right)$ at different time intervals. Further, similar to the findings of present study, Atara et al. (2018) reported increasing trend in motility degeneration rate with increase in preservation time as $6.65 \pm 0.24,13.67 \pm 0.42$ and $28.77 \pm 0.79$ at 30,60 and $120 \mathrm{~min}$, respectively.

Further, Aguiar et al. (2013) observed significantly $(\mathrm{p}<0.05)$ higher motility

\section{REFERENCES}

Aguiar GV, Van Tilburg MF, Catunda AGV, Celes CKS, Lima ICS et al., 2013. Sperm parameters and biochemical components of goat seminal plasma in the rainy and dry seasons in the Brazilian Northeast: the season's influence on the cooling of semen. Brazilian J Vet Anim Sci, 65(1): 6-12

Almeida R and Soares A, 2002. Usage of green coconut water and different tissue culture media for in vitro honey bee semen storage (Apis mellifera degeneration rate (MDR) at 2 hour after cooling $(57.6 \pm 9.1 \%)$ than 48 hours after cooling $(43.5 \pm 9.0 \%)$ during dry season in non-defined breed of bucks. However, they found nonsignificant difference in MDR at 24 hours after cooling $(50.5 \pm 9.1 \%)$ during dry season. Further, contrary to the results of present study, they found non-significant difference in MDR after 2 hours $(28.2 \pm 6.2 \%), 24$ hours $(28.2 \pm 7.3 \%)$ and 48 hour $(27.1 \pm 7.4 \%)$ of time intervals during rainy season.

In conclusion the highest sperm motility was found in treatment group supplemented with 5\% coconut water in tris egg yolk citrate extenders which was further maintained above $50 \%$ up to 36 hours post-chilling in paired cauda epididymal buck spermatozoa preserved at refrigerated temperature proves the favorable effect of coconut water for semen preservation. Further, the lowest motility degeneration rate was found in treatment group supplemented with 5\% coconut water in tris egg yolk citrate extenders at all the time intervals of refrigerated preservation for paired cauda epididymal buck spermatozoa. However, highest overall motility degeneration rate was observed in treatment group supplemented with $20 \%$ coconut water in tris egg yolk citrate extender suggest the harmful effect of coconut water in tris egg yolk citrate extender when supplemented at higher concentration.

Conflict of interest: Authors declare that there is no conflict of interest regarding the present research work.

Hymenoptera: apoidea). Interciencia, 27(6): 317-321

Atara V, Chaudhari C, Ramani U, Chaudhary M, Patel D et al., 2018. Semen characteristics in young and adult Surti buck. Indian J Anim Hlth, 57(2): 219-224

Barros TB and Toniolli R, 2011. Usopotencial da água de coco natecnologia de sêmen. Rev. Bras Reprod Anim, 35: 400-407 
Beltran MAG, Atabay EP, Atabay EC, Cruz EM, Aquino FP et al., 2013. Optimized extenders for cryopreservation of buck semen for artificial insemination. Philippine J Vet Anim Sci, 39(1): $1-10$

Campos ACN, Nunes JF, Monteiro AWU, de Figueiredo EL, Pinheiro JHT et al., 2004. Viability of washed and unwashed goat sperm diluted in coconut water, cooled and storage at $4^{\circ} \mathrm{C}$. Rev Bras Ciênc Vet, 11(3): 178-182

Cardoso RCS, Silva AR and Silva LDM, 2005. Use of the powdered coconut water (ACP-106 ${ }^{\circledR}$ ) for cryopreservation of canine spermatozoa. Anim Reprod, 2(4): 257-262

Daramola JO, Adekunle EO, Oke OE, Onagbesan OM, Oyewusi IK et al., 2016. Effects of coconut (Cocos nucifera) water with or without egg-yolk on viability of cryopreserved buck spermatozoa. Anim Reprod, 13(2): 57-62

El-Sheshtawy RI, El-Nattat WS and Daiem Ali GA, 2017. Cryopreservation of cattle semen using coconut water extender with different glycerol concentrations. Asian Pacific J Reprod, 6(6): 279-282

Ferdinand N, Thomas TT, Augustave K, Henry DF, Fernand T et al., 2012. Effects of buck age, storage duration, storage temperature and diluents on fresh West African Dwarf buck semen. J Reprod Infertil, 3(3): 58-66

Juma PO, 2017. An evaluation of effect of two extenders and storage temperature on quality of Alpine goat semen processed with and without seminal plasma. Master degree thesis submitted to the University of Nairobi, pp44

Lima ICS, Andrade IRA, Aguiar GV, Silva MM, Catunda AG et al., 2013. In vitro evaluation of goat cauda epididymal sperm, cooled in different extenders at $4^{\circ} \mathrm{C}$. Archivos de zootecnia, 62(239): 429-437

Luzardo B, Castro MC, Gamboa FA, Lopez MA and Lopez AYRA, 2010. Osmolarity of coconut water (Cocos nucifera) based diluents and their effect over viability of frozen boar semen. Am J Anim Vet Sci, 5(3): 187-191

Mayombo PVK, 2017. Evaluation of Nguni bull semen extended in tris egg yolk extender, soybean milk and coconut water based extenders and stored at different temperatures. Master degree thesis submitted to University of Venda South Africa, pp35

Nunes JF and Combarnous Y, 1995. Utilização da água de coco e de suas frações ativas como diluidor de sêmen de mamíferos domésticos. Cienc Anim, 2: $15-21$

Puja IK, Sawitri NM, Maharani N, Gunawan IWNF and Heryani LGSS, 2018. A comparative study on the effects of coconut water based extenders on the quality of Kintamani dog semen preserved at $4^{\circ} \mathrm{C}$. Adv Anim Vet Sci, 6(5): 192-196

Silva MA, Peixoto GCX, Santos EAA, Castelo TS, Oliveira MF et al., 2011. Recovery and cryopreservation of epididymal sperm from agouti (Dasiproctaaguti) using powdered coconut water (ACP-109c) and tris extenders. Theriogenology, 76: 1084-1089

Yimer N, Noraisyah A, Rosnina Y, Wahid H, Sarsaifi K et al., 2014. Comparison of cryopreservative effect of different levels of omega-3 egg-yolk in citrate extender on the quality of goat spermatozoa. Pakistan Vet J, 34(3): 347-350

Yong JWH, Ge L, Ng YF and Tan SN, 2009. The chemical composition and biological properties of coconut (Cocos nucifera L.) water. Molecules, 14(12): 5144-5164 